\title{
Changes in the Seasonal Cycle in the Circumpolar Arctic, 1976-95: Temperature and Precipitation
}

\author{
PAUL H. WHITFIELD, ${ }^{1,2}$ ALEXANDER W. HALL ${ }^{3}$ and ALEX J. CANNON ${ }^{1}$
}

(Received 30 January 2003; accepted in revised form 24 July 2003)

\begin{abstract}
The Arctic is one region where the effects of global climate change are expected to be easy to observe. This study identifies regions in the circumpolar Arctic that have experienced similar changes in the seasonal cycle of temperature and precipitation over recent decades. Data from Arctic and northern nations have been compiled to form a new data set of over 1200 circumpolar Arctic climate stations. Changes in the seasonal cycle between two decades (1976-85 and 1986-95) are examined for the 247 temperature and 555 precipitation stations that meet specific completeness criteria. Inter-decadal shifts are analyzed using 11-day averages of daily mean temperature and 5-day averages of total daily precipitation. Examined at time-steps finer than annual or monthly means, climatic variations in the region are not consistent either through the seasons or across space. Some areas have demonstrated recent increases in temperature or precipitation, while others have displayed decreases in these elements. Many areas reveal climatic shifts in specific periods of the year that contrast markedly with the trends observed in other periods and other places.
\end{abstract}

Key words: k-means clustering, spatial patterns, cohesion, temperature, precipitation, Arctic climate

RÉSUMÉ. L'Arctique est une région où il devrait être relativement facile d'observer les effets du changement climatique mondial. Cette étude inventorie les régions de l'Arctique circumpolaire qui ont connu des changements similaires dans le cycle saisonnier de température et de précipitation au cours des dernières décennies. Des données provenant de nations de l'Arctique et du Nord ont été compilées en vue de créer un nouvel ensemble de données issues de plus de 1200 stations climatiques de l'Arctique circumpolaire. On examine les changements dans le cycle saisonnier entre deux décennies (1976-1985 et 1986-1995) pour les 247 stations de température et les 555 stations hyétométriques qui répondent aux critères spécifiques d'intégralité. On analyse les décalages entre les deux décennies en utilisant les moyennes sur 11 jours de la température quotidienne moyenne, ainsi que les moyennes sur cinq jours de la précipitation quotidienne totale. Si on les examine à des pas de temps plus petits que les moyennes annuelles ou mensuelles, les variations climatiques dans la région ne sont pas cohérentes, que ce soit en fonction des saisons ou de l'espace. Certaines zones ont affiché de récentes hausses de température ou de précipitation, tandis que d'autres ont enregistré des baisses de ces mêmes paramètres. Un grand nombre de régions montrent des changements de climat durant des périodes spécifiques de l'année, changements qui contrastent de façon très nette avec les tendances observées à d'autres moments et en d'autres lieux.

Mots clés: classification automatique à K moyennes, schémas spatiaux, cohérence, température, précipitations, climat arctique

Traduit pour la revue Arctic par Nésida Loyer.

\section{INTRODUCTION}

It is predicted that the greatest response to global climate warming will occur at high latitudes, and some evidence of such polar amplification has already been observed (Polar Group, 1980; Jager and Kellogg, 1983; Rouse et al., 1997; Kattsov and Walsh, 2000; Rigor et al., 2000; IPCC, 2001). Rigor et al. (2000) propose that changes in global climate will be first and most readily detected in polar regions. Shifts in climate patterns will affect all major hydrologic and ecological processes in the Arctic and may evoke strong responses. Hydrologic impacts will be greatest in regional or seasonal settings in which temperatures historically below the freezing level rise to above freezing. Beyond contributing to shifts in regional and global climate mechanisms, these changes will have ecological, social, and economic implications.

Recent studies have shown that Arctic temperature and precipitation have generally increased during the 20th century, especially in the latter decades (Bradley et al., 1987; Hurrell, 1995; IPCC, 2001). Paeth et al. (2002) noted that many of the studies reporting 20th century Arctic warming trends were based on annual results and therefore failed to detect more subtle changes. Changes in the seasonal cycle and timing of climatic events could potentially have large impacts on northern ecosystems.

\footnotetext{
${ }^{1}$ Meteorological Service of Canada, Environment Canada, \#201 - 401 Burrard Street, Vancouver, British Columbia V6C 3S5, Canada

${ }^{2}$ Corresponding author: Paul.Whitfield@ec.gc.ca

${ }^{3}$ Department of Geography, Simon Fraser University, 8888 University Drive, Burnaby, British Columbia V5A 1S6, Canada

(C) The Arctic Institute of North America and Environment Canada
} 


\section{Climate Stations:}

$\begin{array}{cl}\odot & \begin{array}{l}\text { Temperature } \\ \text { and Precipitation }\end{array} \\ \oplus & \text { Temperature only } \\ \oplus & \begin{array}{l}\text { Precipitation only } \\ \text { ACIA } \\ \text { Arctic } \\ \text { Boundary }\end{array}\end{array}$

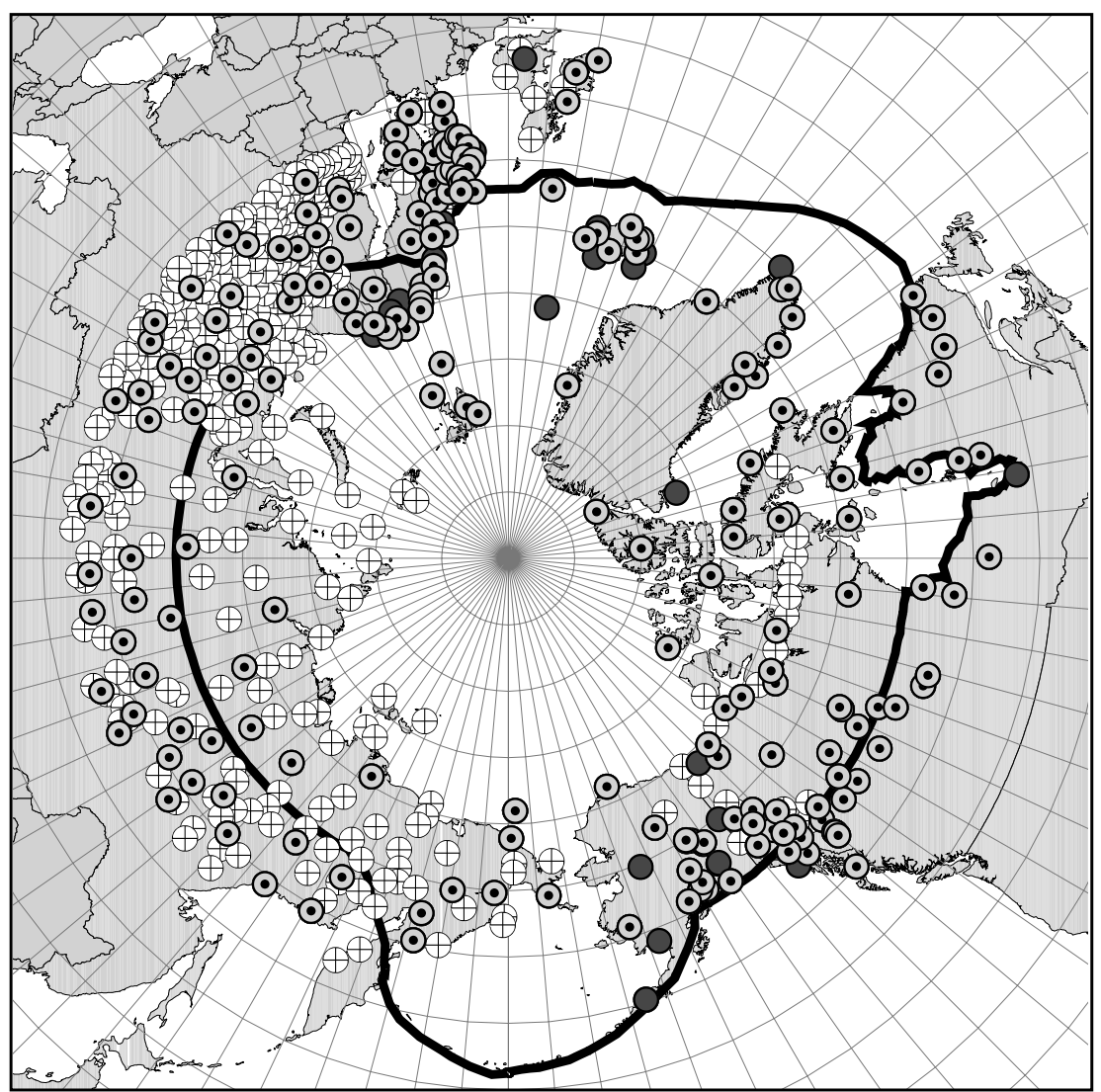

FIG. 1. Temperature and precipitation stations in the circumpolar Arctic. $\left(0^{\circ}\right.$ longitude is at the top of the figure.)

The North has unique ecosystems; productivity is lower, diversity and energy transfers are lower, seasonal variability and climate are extreme, and there is a general paucity of knowledge and baseline information (J. Reist, pers. comm. 2003). Walther et al. (2002) suggest that global averages may not predict effects on particular organisms, populations, and communities, since they respond to local changes that are heterogeneous. Variations in temperature affect plant phenology (e.g., Ahas et al., 2002; Cayan et al., 2002; Schwartz et al., 2002) and synchronization of species (e.g., Grenfell et al., 1998; Milner et al., 1999; Post and Forchhammer, 2002).

Statistical techniques to identify changes in seasonality and timing of hydroclimatic events were proposed by Leith and Whitfield (1998) and Whitfield and Taylor (1998). Whitfield and Cannon (2000a) extended this methodology by applying a statistical clustering procedure to identify regions in Canada that exhibited similar changes in the seasonal cycle of temperature, precipitation, and streamflow. It was felt that monthly averages could not accurately resolve the decadal patterns of change for temperature or precipitation; however, five-day averages of daily streamflow data provided detailed information about changes in hydrologic regimes and timing of hydrologic events. Whitfield et al. (2002) demonstrated that by using shorter averaging periods, they could enhance the separation of spatial clusters showing patterns of seasonal change in temperature and precipitation.
This study identifies regions of the circumpolar Arctic that have experienced similar changes in the seasonal cycle of temperature and precipitation over recent decades. Trend analysis and cluster analysis methods used by Whitfield and Cannon (2000a) and Whitfield et al. (2002) are updated and applied to a newly assembled data set of daily observations from Arctic climate stations. Data for the period 1976-95 have been compiled from more than 1200 stations located across the North. Previous work focused on individual countries; this study focuses on the circumpolar Arctic spanning many countries. The spatial distribution of recent variations in the climate system may have higher-order effects on ecosystems of the North. It is anticipated that results from this study will help to analyze observations of recent ecological change. While these two decades of records are insufficient to determine long-term trends, they do provide a large enough contemporary data set to allow examination of spatial patterns of change.

\section{DATA}

Daily mean temperature and total daily precipitation records were obtained from climatic stations for the circumpolar Arctic for the decades 1976-85 and 1986-95. These two decades were chosen to coincide with the results of earlier studies by Whitfield et al. (2002), Whitfield (2001), and Whitfield and Cannon (2000a). This period also coincides 
TABLE 1. Distribution of temperature and precipitation stations by country or territory, indicating approximate spatial coverage and the density of study stations.

\begin{tabular}{|c|c|c|c|c|c|c|}
\hline \multirow[t]{2}{*}{ Country or Territory } & \multirow{2}{*}{$\begin{array}{l}\text { Approximate } \\
\text { Coverage } \\
\left(1000 \mathrm{~km}^{2}\right)\end{array}$} & \multicolumn{2}{|c|}{ Temperature Stations } & \multicolumn{2}{|c|}{ Precipitation Stations } & \multirow[t]{2}{*}{ Data Source } \\
\hline & & $\#$ & $\begin{array}{c}\text { Density } \\
\left(\# / 1000 \mathrm{~km}^{2}\right)\end{array}$ & $\#$ & $\begin{array}{c}\text { Density } \\
\left(\# / 1000 \mathrm{~km}^{2}\right)\end{array}$ & \\
\hline Canada & 6080.0 & 63 & 0.010 & 83 & 0.014 & Meteorological Service of Canada \\
\hline Denmark & 42.7 & 3 & 0.070 & 6 & 0.141 & European Climate Assessment \\
\hline Estonia & 45.5 & 1 & 0.022 & 16 & 0.352 & U.S. National Climate Data Center \\
\hline Faroe Islands & 1.4 & 1 & 0.714 & 1 & 0.714 & Danish Meteorological Institute \\
\hline Finland & 333.8 & 3 & 0.009 & 3 & 0.009 & European Climate Assessment \\
\hline Greenland & 2142.7 & 11 & 0.005 & 9 & 0.004 & $\begin{array}{l}\text { Danish Meteorological Institute, } \\
\text { U.S. National Climate Data Center }\end{array}$ \\
\hline Iceland & 101.8 & 11 & 0.108 & 7 & 0.690 & $\begin{array}{l}\text { European Climate Assessment, } \\
\text { U.S. National Climate Data Center }\end{array}$ \\
\hline Ireland & 69.4 & 3 & 0.043 & 3 & 0.043 & European Climate Assessment \\
\hline Latvia & 47.5 & 0 & 0.000 & 12 & 0.253 & U.S. National Climate Data Center \\
\hline Norway & 317.0 & 47 & 0.148 & 45 & 0.142 & $\begin{array}{l}\text { Norwegian Meteorological Institute, } \\
\text { European Climate Assessment }\end{array}$ \\
\hline Russia & 11300.0 & 68 & 0.006 & 337 & 0.030 & U.S. National Climate Data Center \\
\hline Svalbard & 3.1 & 4 & 1.290 & 4 & 1.290 & Norwegian Meteorological Institute \\
\hline Sweden & 443.8 & 5 & 0.011 & 6 & 0.014 & European Climate Assessment \\
\hline U.K. & 243.1 & 1 & 0.004 & 5 & 0.021 & European Climate Assessment \\
\hline U.S.A. & 1480.0 & 26 & 0.018 & 18 & 0.012 & U.S. National Climate Data Center \\
\hline
\end{tabular}

with the period of greatest global warming during the 20th century (IPCC, 2001), the subject of numerous studies of ecological change in the Arctic. Many climate stations have a much longer record of good-quality data; however, an extension of the study period would significantly reduce the spatial coverage and measurement density.

Preliminary station selection was based on the northern high-latitude region as defined by the Arctic Climate Impact Assessment (ACIA) (AMAP, 1998). This boundary excluded some regions important to an examination of Arctic climate change, particularly northeastern Canada, the southern shore of Hudson Bay, and the southern twothirds of the Scandinavian nations. To accommodate these regions, the ACIA boundaries were relaxed southwards by roughly five degrees (more in Scandinavia and less in North America). This change extended the study area to include all land areas adjacent to polar seas and substantially increased data availability. Only a few stations-in southern Scandinavia, the United Kingdom, Ireland, and Canada (on the southern shores of Hudson Bay) - are south of $57^{\circ} \mathrm{N}$. Figure 1 shows the locations of the 802 climate stations used in the clustering procedure.

Daily temperature and precipitation data sets for Denmark, Finland, Iceland, Ireland, Norway, Sweden, and the United Kingdom were obtained from the European Climate Assessment. Data sets for additional Norwegian climate stations were obtained from the Norwegian Meteorological Institute. The Danish Meteorological Institute provided data for Greenland stations. The data for Greenland and Iceland were supplemented with additional station records from the U.S. National Oceanic and Atmospheric Administration's National Climate Data Center (NCDC). Alaskan and Russian data were also provided by NCDC. Northern Canadian stations were selected from the climate archives of the Meteorological Service of Canada.
TABLE 2. Completeness of final data sets for the two decades. The values indicate the percentage of time periods that had each degree of completeness. There were 247 temperature stations with 33 eleven-day periods and 555 precipitation stations with 73 five-day periods.

\begin{tabular}{lcccccc}
\hline \hline & \multicolumn{5}{c}{ Percentage Completeness } \\
\cline { 2 - 7 } & $100 \%$ & $90 \%$ & $80 \%$ & $70 \%$ & $60 \%$ & $<60 \%$ \\
\hline Temperature & & & & & & \\
$1976-85$ & 88.2 & 6.9 & 4.0 & 0.7 & 0.2 & 0.0 \\
$1986-95$ & 78.2 & 8.1 & 8.6 & 3.7 & 1.4 & 0.0 \\
Precipitation & & & & & & \\
$1976-85$ & 68.6 & 23.8 & 6.6 & 1.0 & 0.1 & 0.0 \\
$1986-95$ & 48.2 & 13.1 & 18.1 & 14.5 & 6.2 & 0.0 \\
\hline \hline
\end{tabular}

Each individual data set has been subjected to different quality control methods, as performed by each respective agency. Data sets were used as provided; no attempt was made to remove possible heterogeneity resulting from changes in measuring technique, station environment, or location during the period of record. Whitfield et al. (2002) showed that such datasets in Canada for the period 197695 provided results similar to those from data sets that had been homogenized to remove inconsistencies. Table 1 summarizes the locations of the 802 stations used in the clustering procedure, lists the data sources, and illustrates some of the discrepancies in data availability.

Calculations of temperature and precipitation series were based on 11-day and 5-day averages, respectively. Whitfield et al. (2002) concluded that the application of these time-steps to larger sets of climate stations resulted in better resolution of the patterns of temperature and precipitation changes between decades than could be obtained from monthly or annual series. We obtained data for 441 temperature stations and 802 precipitation stations that contained records for the two decades being examined; 

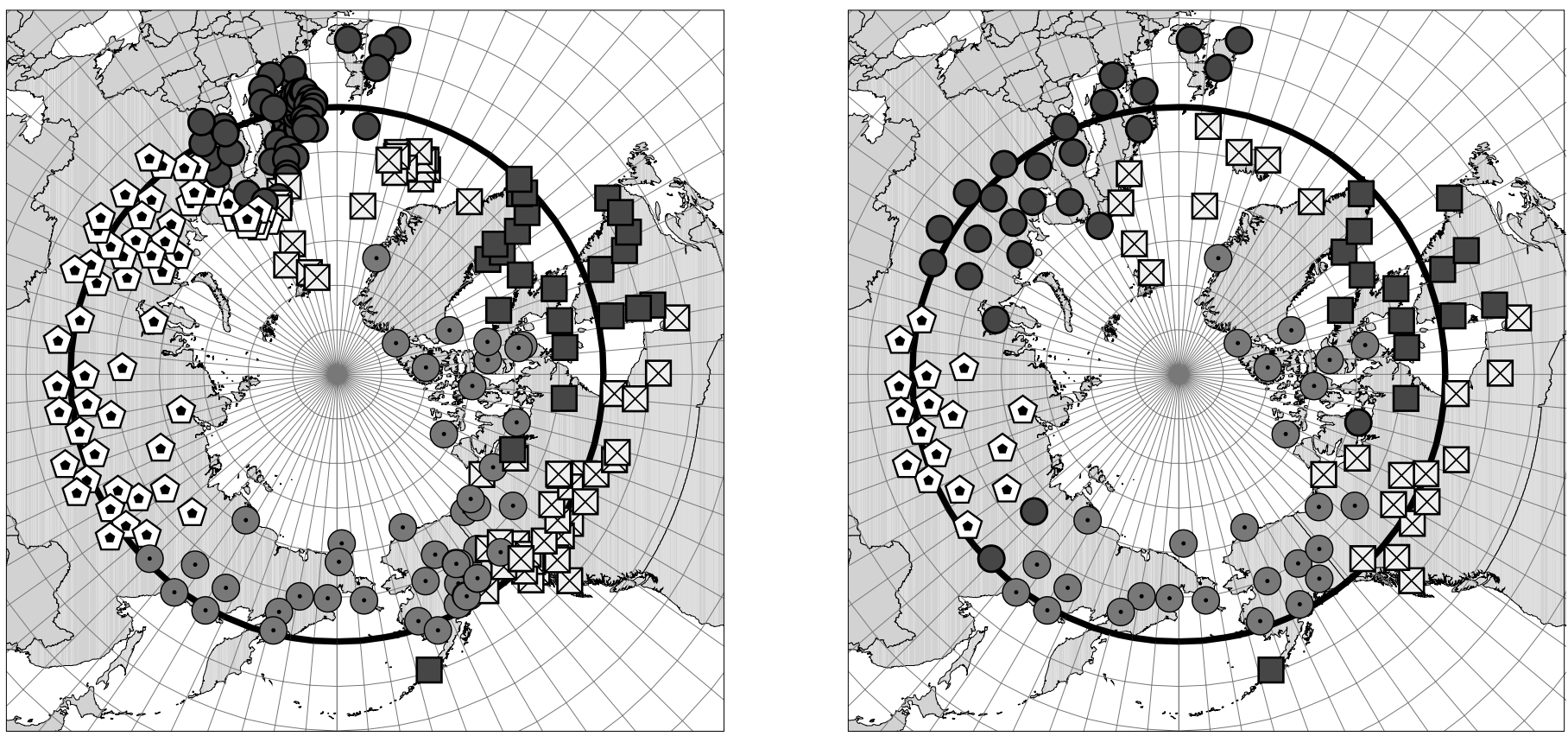

FIG. 2. Temperature stations clustered at the five-cluster level are displayed on the left. Temperature stations reselected with a $300 \mathrm{~km}$ threshold and clustered at the five-cluster level are displayed on the right. Symbols indicate cluster membership. ( $\left(0^{\circ}\right.$ longitude is at the top of the figure.)

however, stations with less than six years of data in either decade were rejected from further inclusion in this study. For each station, two criteria were evaluated. First, any individual 5-day or 11-day period within a specific year that was missing more than $20 \%$ of its daily values did not have a period mean calculated and was therefore removed from further analysis. Second, any specific period with period means either missing or removed from more than four years in a given decade did not have a decadal median calculated and was not included in the statistical analysis. The only stations included in the cluster analysis were those for which a decadal median had been calculated for every period in both decades. This same procedure was employed by Whitfield et al. (2002). The cluster analysis incorporated 247 temperature stations and 555 precipitation stations. Table 2 contains a summary of stations with greater than $80 \%$ completeness over all time periods for the two decades. More than $95 \%$ of the temperature records and about $90 \%$ of precipitation records are complete.

\section{METHODS}

The techniques employed to detect significant differences in temperature and precipitation between the two decades are described by Leith and Whitfield (1998) and Whitfield et al. (2002). Decadal median values were calculated for each period in each decade. The statistical significance of differences between the decadal median values was then determined using the Mann-Whitney U test, a nonparametric, rank-based test that is robust against nonnormality in distributions of the two test samples. Annual series of the period median values were not pre-whitened before statistical testing, despite the fact that serially correlated noise can affect trend analyses based on the Mann-Whitney U test (Fleming and Clarke, 2002). As Fleming and Clarke (2002) point out, deserialization is appropriate only if strong a priori evidence suggests the presence of autoregressive noise in a series; such evidence is not clear for the annual series analyzed in this study. For each period at each station, the median values of each decade, the level of significance $p$ of the test, and the sign of the observed change in the decadal median value were recorded for subsequent use in the cluster analysis.

To distinguish regions exhibiting similar changes in the seasonal cycle of temperature and precipitation, results from the significance test were clustered using the global k-means algorithm (Likas et al., 2003). The global kmeans algorithm was selected to improve clustering performance and to reduce the influence of initial seed selection on the cluster solutions. The incremental method of the global k-means algorithm and its deterministic technique of adding a globally optimal cluster centroid at each new level eliminate subjectivity due to choice of initialization method. Temperature and precipitation data sets were clustered independently. For entry into the cluster analysis, values of $(1-p)$ were multiplied by the sign of the observed change for each individual time period. This resulted in a normalized index for decadal changes in both 5-day precipitation amounts and 11-day temperatures. The use of this type of index is similar in spirit to Karl and Riebsame's (1984) use of a $t$-statistic index to identify decadal changes in seasonal and annual precipitation and temperature series, or Molnár and Ramírez's (2001) use of a Z-score index to characterize patterns of change in monthly streamflow. 


\section{Temperature Stations: 5 Clusters

$\begin{array}{cr}\otimes & \text { Cluster } 1 \\ \odot & \text { Cluster 2 } \\ - & \text { Cluster } 3 \\ \square & \text { Cluster } 4 \\ \odot & \text { Cluster } 5\end{array}$ \\ $-60^{\circ} \mathrm{N}$}

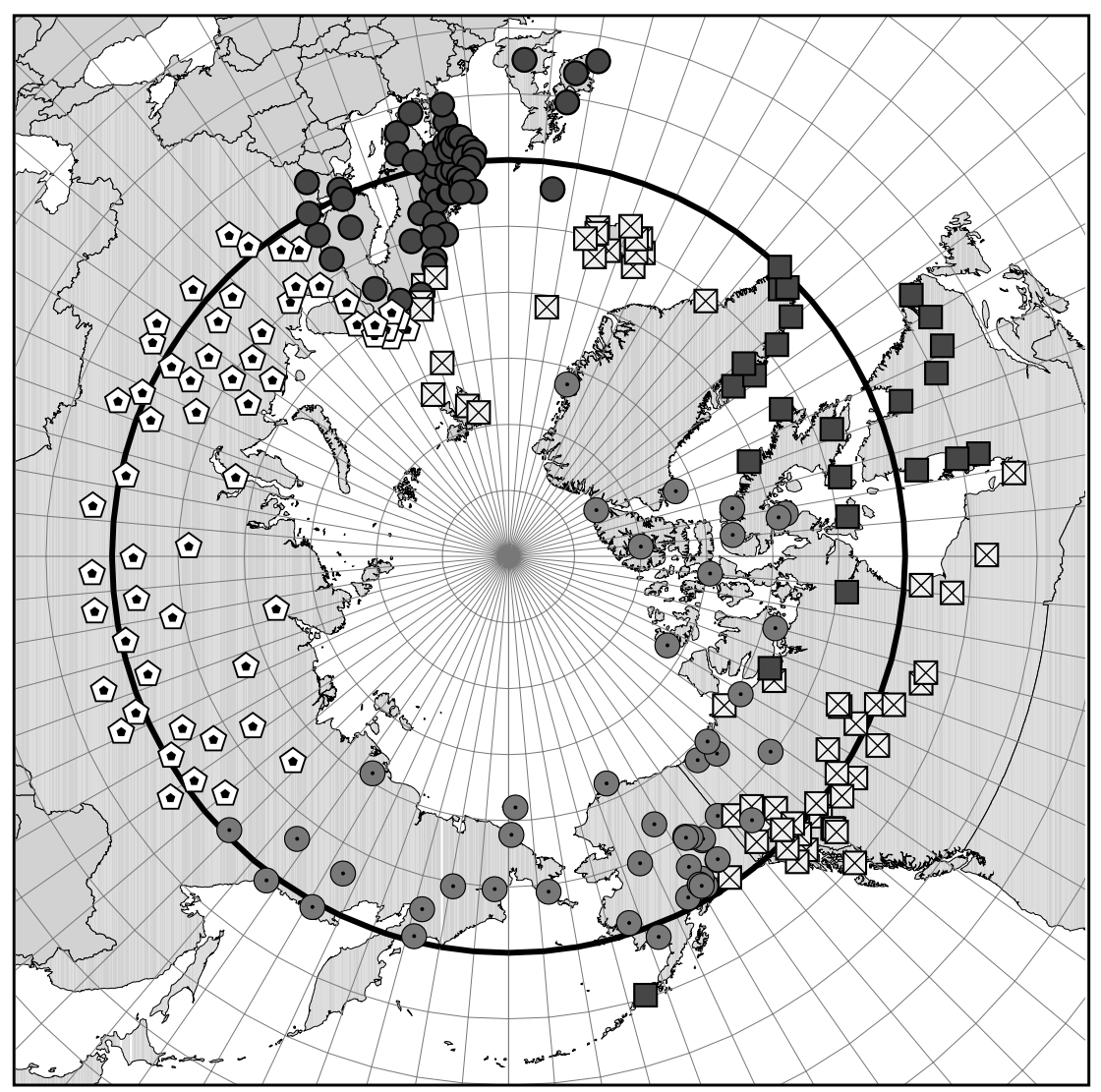

FIG. 3. Temperature stations clustered at the five-cluster level. $\left(0^{\circ}\right.$ longitude is at the top of the figure.)

\section{Precipitation Stations: 4 Clusters}

$\begin{array}{ll}\triangle & \text { Cluster 1 } \\ \Delta & \text { Cluster 2 } \\ \triangle & \text { Cluster 3 } \\ \bullet & \text { Cluster 4 } \\ -\quad 60^{\circ} \mathrm{N}\end{array}$

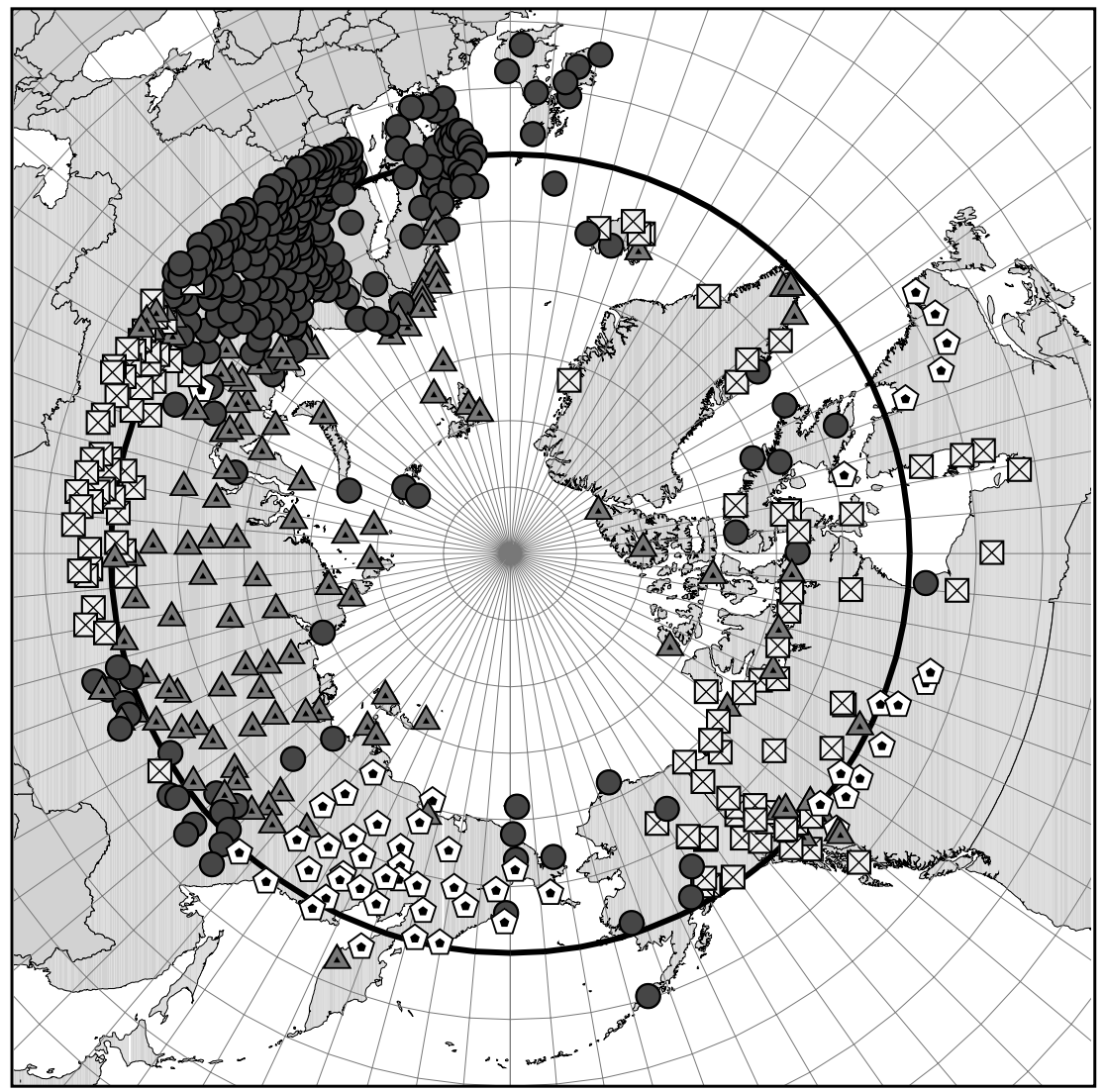


Preliminary clustering of unweighted results generated clusters that were substantially biased towards regions of high station density. Furthermore, these centres were located outside the predefined Arctic region, in adjacent areas (e.g., southern Russia and southern Norway), biasing the clustering towards the most southern regions of the study area. To offset the effects of the uneven spatial distribution of observation sites, each station was assigned a coefficient based on its relative isolation to determine how much weight it would be assigned in the clustering algorithm. First, the distance to the $n$ nearest geographical neighbours of each station was calculated. Second, the mean distance to the $n$ nearest neighbours and the square of the mean distance to the $n$ nearest neighbours were calculated. Last, the distance values were rescaled to obtain a weighting factor for each station. In this approach, stations of greater relative isolation would contribute greater numbers of "virtual" stations to the clustering process. As a method of assessing the validity of the weighting scheme, the number of virtual stations within a $1000 \mathrm{~km}$ radius was calculated for each station. This was repeated with weighting factors based on the mean distance and the square of the mean distance to the $1,2,5$, and 10 nearest neighbours and rescaled to a selection of intervals. The weighting factors were assessed by plotting the number of station copies located within $1000 \mathrm{~km}$ of each station against the mean distance to its $n$ nearest neighbours (not shown). This procedure compared the relative contribution of each study station to the clustering process to its relative isolation from other real stations. It was determined that using factors based on the square of the mean distance to the station's five nearest neighbours, scaled from 1 to 50 for temperature and from 1 to 150 for precipitation, minimized the ratio between the maximum and minimum number of stations with a $1000 \mathrm{~km}$ radius. These factors provided sufficiently representative data coverage for this study. This method is a simple scheme, yet it provided substantial reduction of the station distribution bias.

To assess the success of our weighting scheme, we compared the two clustering solutions thus achieved with two others derived using an alternative method that selected a more evenly distributed subset of stations. We randomly selected a station, removed all stations within a threshold distance, calculated the nearest-neighbour distances between remaining stations, selected one of the pair of stations with the smallest nearest-neighbour distance, and repeated until no further stations could be removed. The result was a subset in which the station distribution was roughly equidistant. A threshold distance of $300 \mathrm{~km}$ for temperature stations and $200 \mathrm{~km}$ for precipitation stations performed well.

For temperature stations, Figure 2 illustrates the similarity between the cluster solutions based on the original data set and the reselected subset. The notable difference between the two solutions is that in the reselected subset, the stations of western Russia are grouped with Scandinavia instead of with central Russia as they are in the weighted case. Other differences in clustering are small in number and occur at the edges of clusters. Overall, $82 \%$ of the stations in the reselected temperature subset were assigned to the same clusters as in the complete weighted data set; $76 \%$ of the precipitation stations were similarly assigned.

The number of clusters to be retained was determined using the consensus of three separate stopping measures as guidance. The three indices used were the TraceW index (Milligan and Cooper, 1985), the C-index (Hubert and Levin, 1976), and that of Calinski and Harabasz (1974), all as adapted by Weingessel et al. (2002). These specific indices were chosen to be representative of the three major classes of stopping measures as defined by Weingessel et al. (2002). Each adapted separation measure was calculated for numbers of clusters ranging from 2 to 20 . The most suitable cluster levels for temperature and precipitation were determined from a comparison of the top three results for each index and the visual inspection of the spatial arrangement of clusters.

\section{RESULTS}

For both temperature and precipitation data, the results of the stopping measures indicated that the two-cluster solution would be the "best" level. However, the spatial distribution of two clusters severely restricted the ability to assess regional patterns. Furthermore, as the three stopping indices used were computed using second differences, the two-cluster solution would be the first recommendation most frequently, as the differences between index values are usually greatest among the first three clusters. Regarding temperature stations, the next two levels of clustering suggested by the consensus of indices were four and five clusters. We decided to retain five clusters because the step from four to five clusters encompasses a significant division of the least contiguous cluster at the four-cluster level. This separated sites from Scandinavia and the British Isles, from Iceland and Svalbard, and from Canada into different clusters (Fig. 3). For precipitation results, the next best level indicated was four clusters. Interestingly, all precipitation solutions with more than four clusters incorporate single-member clusters. The five-cluster solution for temperature stations and the four-cluster solution for precipitation stations are illustrated in Figures 3 and 4.

Figures 5 to 9 illustrate the statistical composition and geographical expression of each cluster, for each climate element and level of clustering. The box plots illustrate the range of variability within each cluster for each period. Sample stations chosen represent those nearest to the cluster centroid and have been displayed in polar plot format, as described by Whitfield and Cannon (2000b).

\section{Temperature Cluster Results}

The weighted results from 247 temperature stations were included in the clustering process; five clusters were 
Cluster $1(\mathrm{~N}=387)$
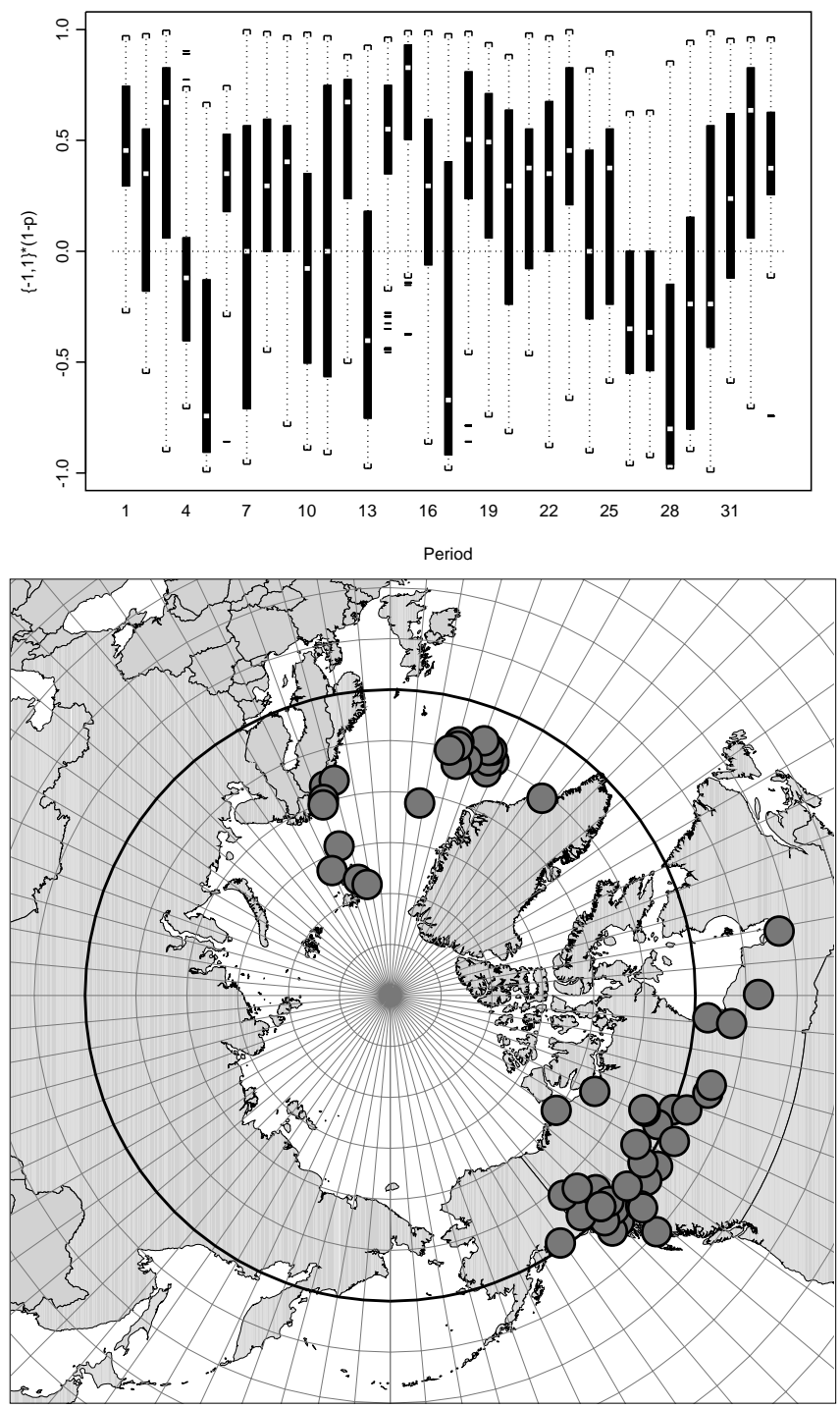

Decadal temperature - daily mean data: 11 day averages 99710 BJOERNOEYA, NORWAY

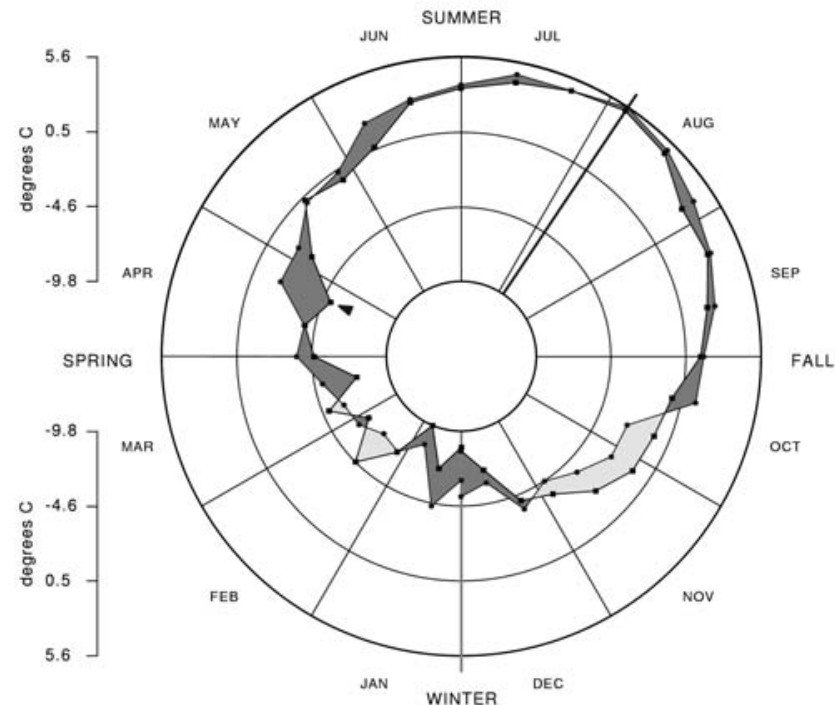

Cluster $2(\mathrm{~N}=701)$

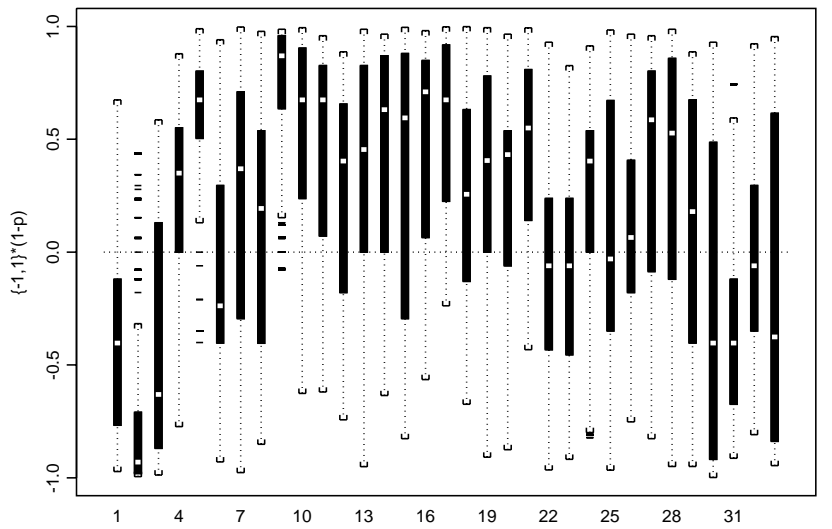

Period
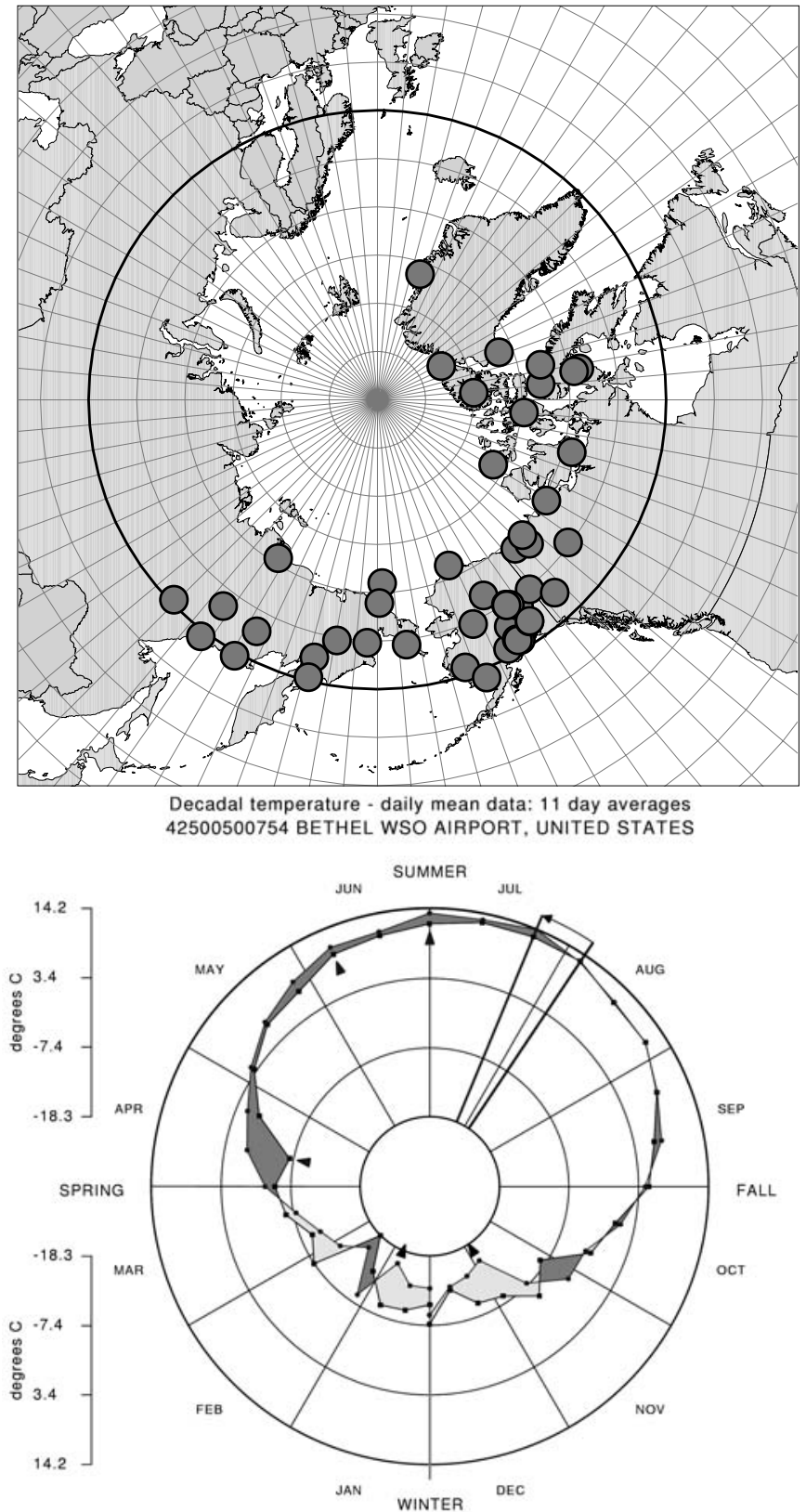

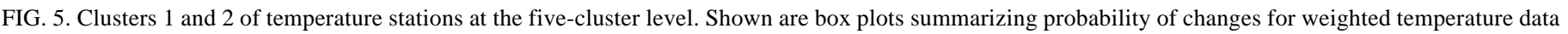

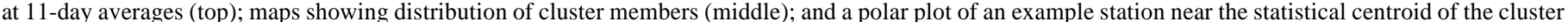

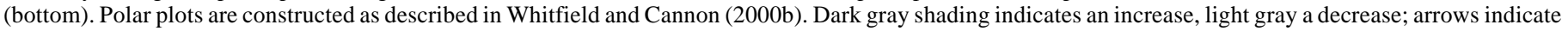
significant increases and decreases. 
Cluster $3(\mathrm{~N}=581)$
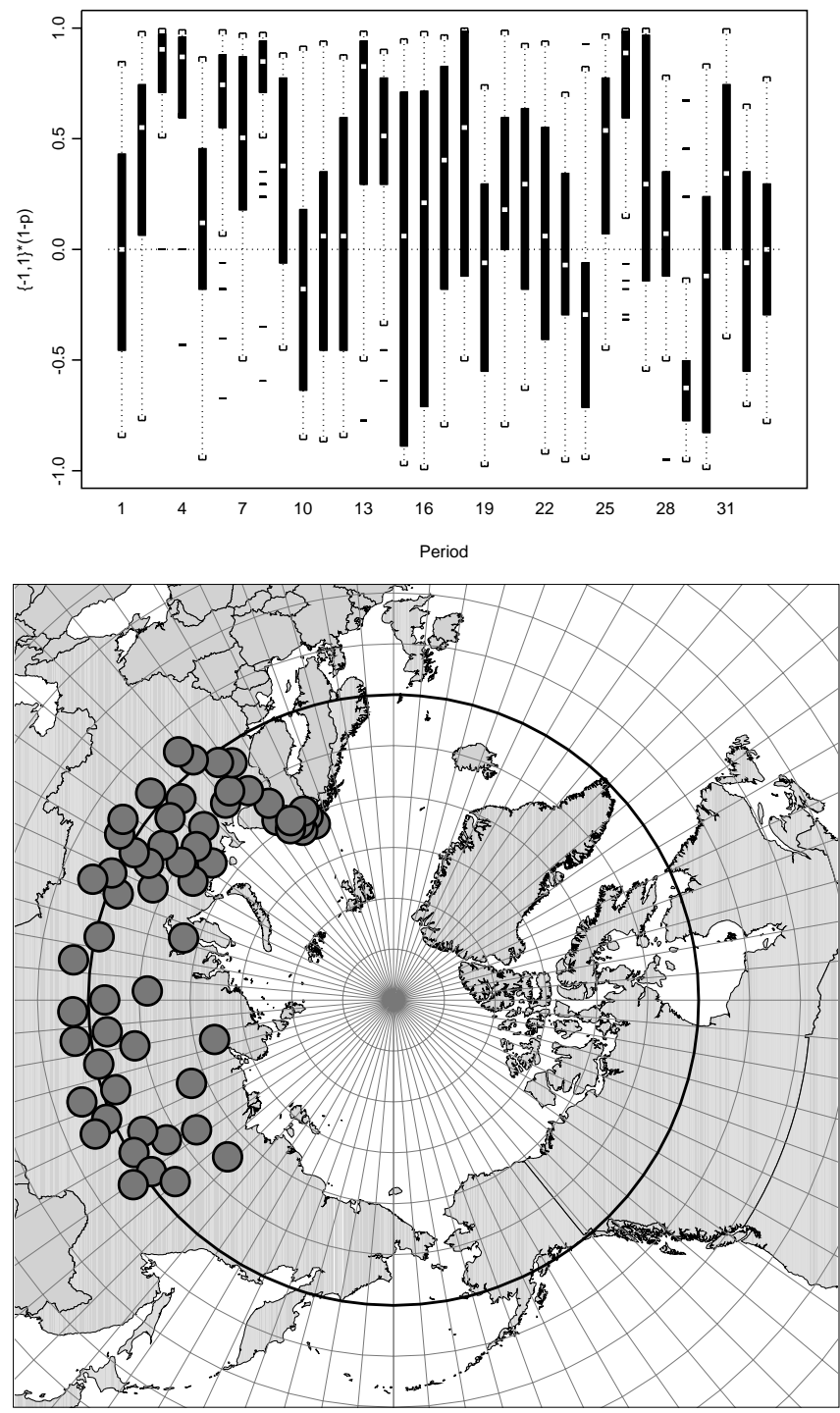

Decadal temperature - daily mean data: 11 day averages 22200022641 ONEGA, RUSSIA

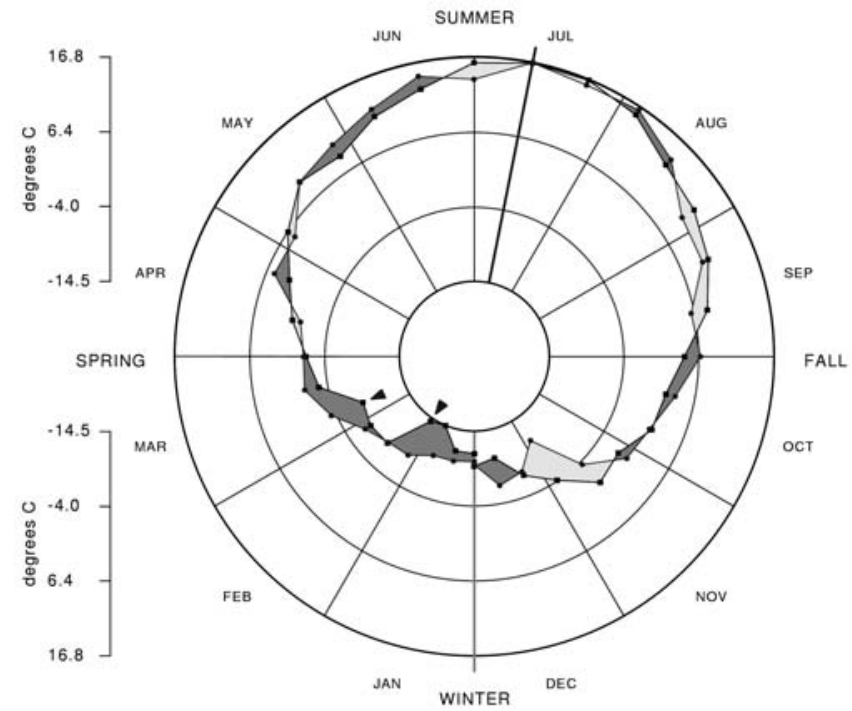

Cluster $4(\mathrm{~N}=368)$
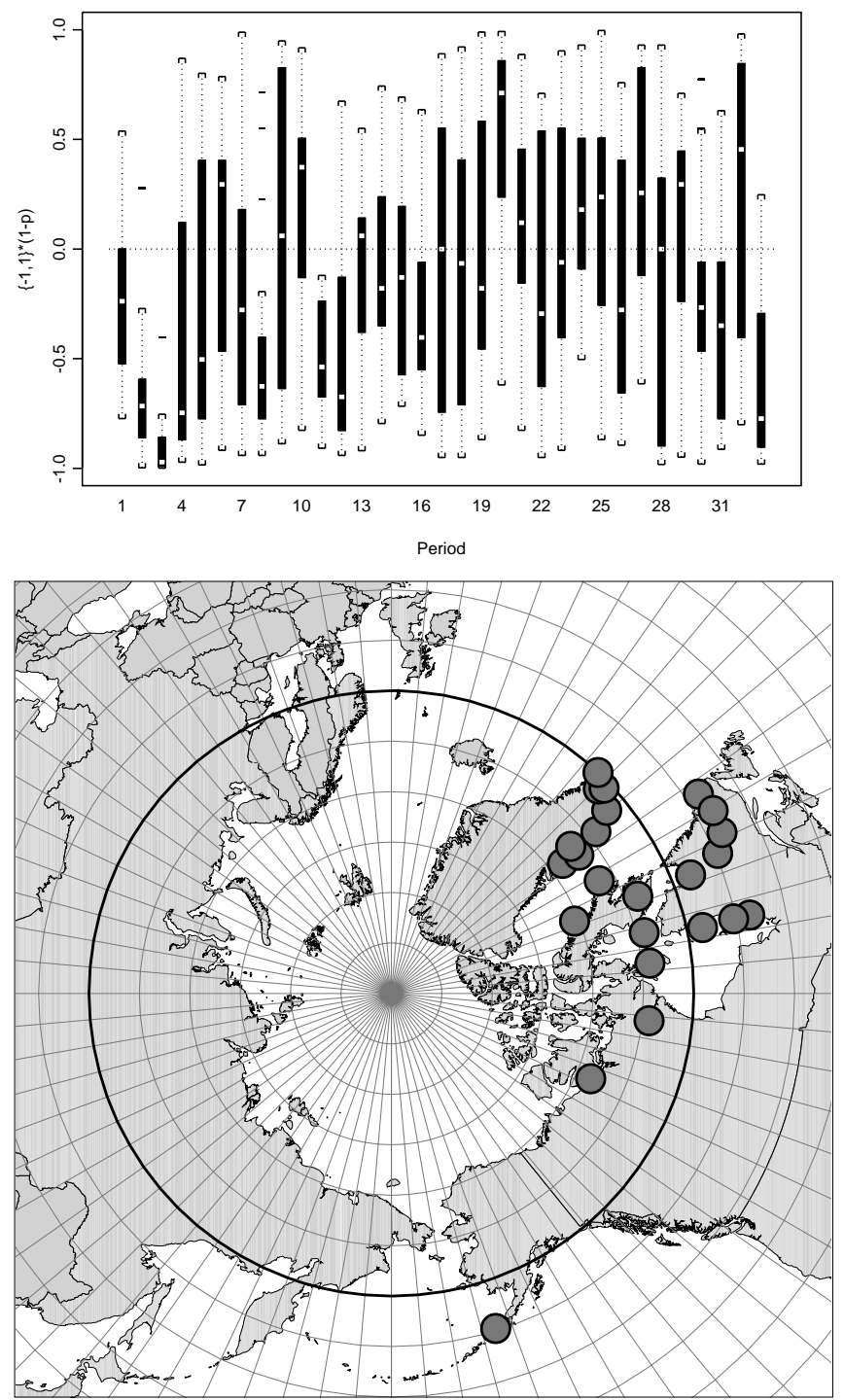

Decadal temperature data: 11 day averages 2402590, IQALUIT A, NU

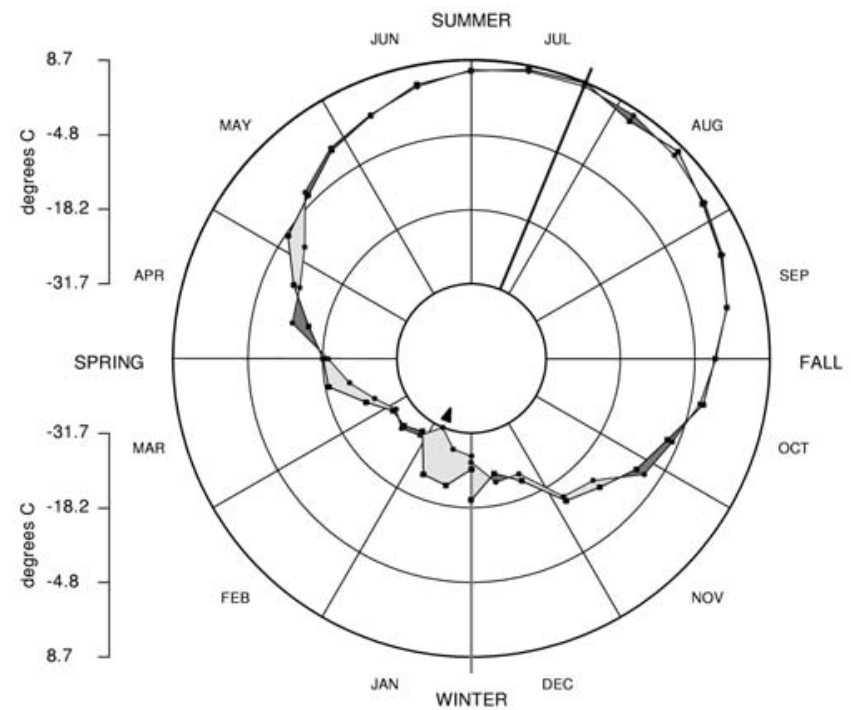

FIG. 6. As in Fig. 5, but for clusters 3 and 4 of temperature stations at the five-cluster level. 

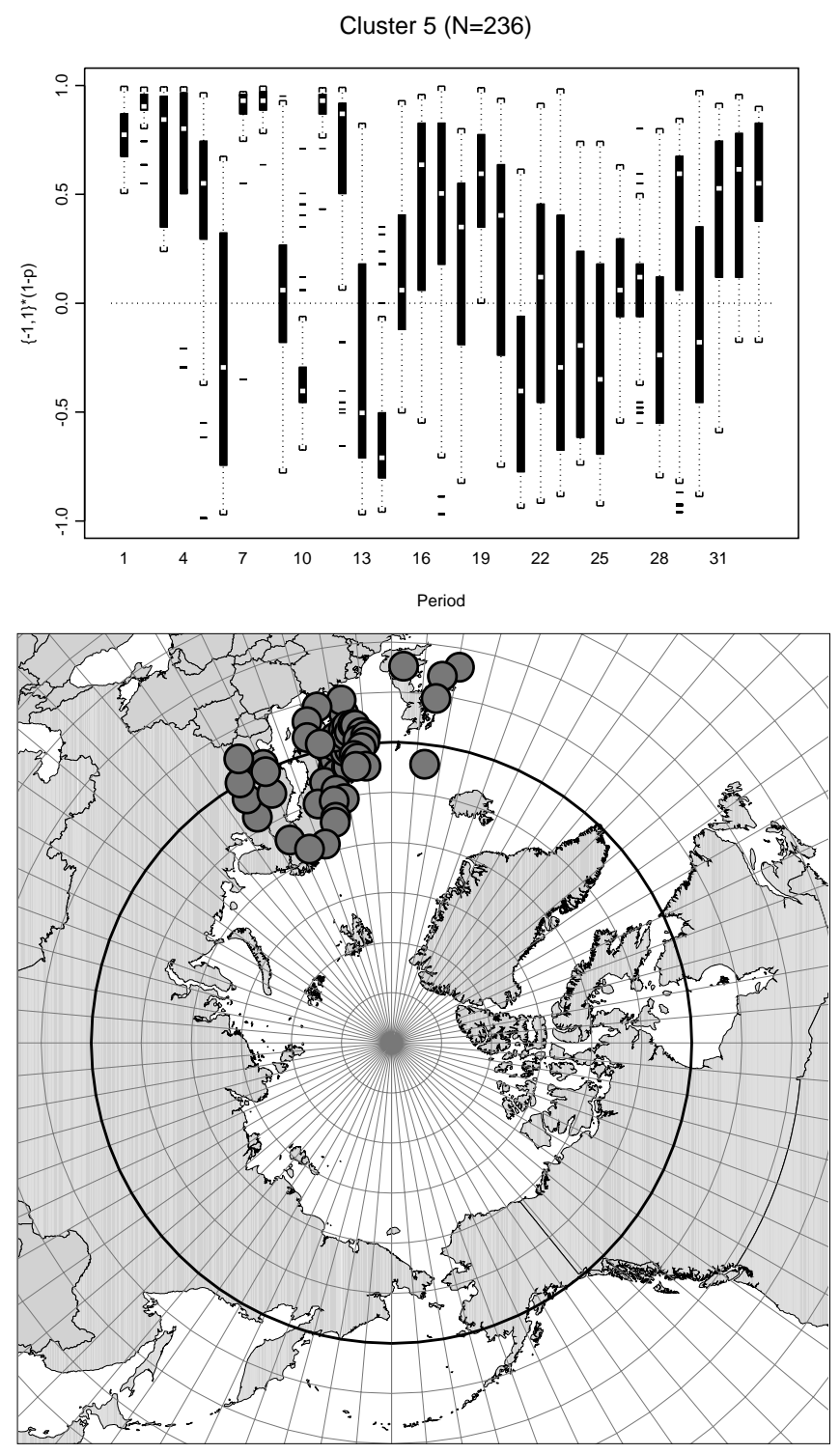

Decadal temperature data: 11 day averages 2402590, IQALUIT A, NU

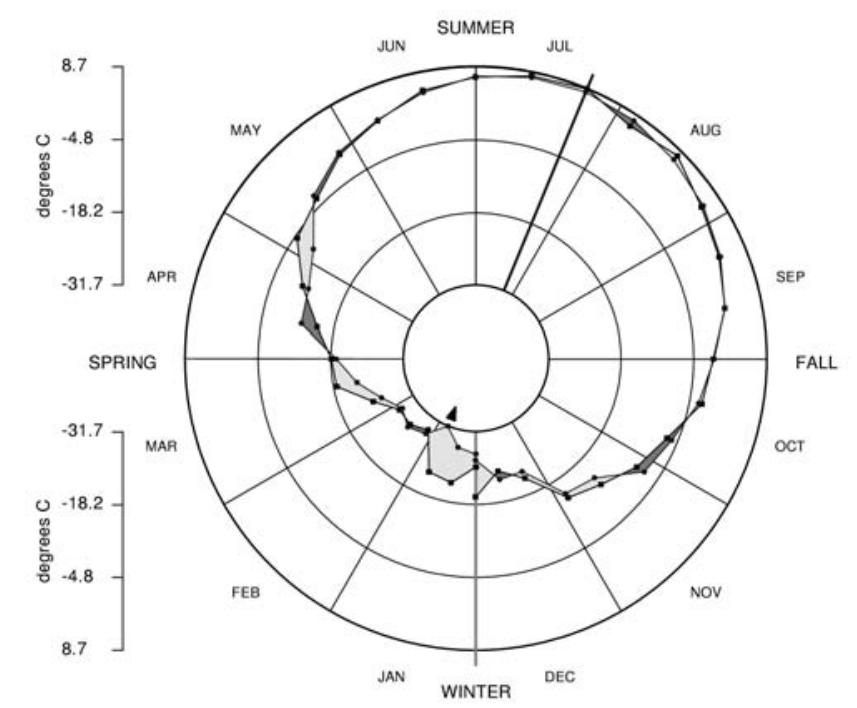

FIG. 7. As in Fig. 5, but for cluster 5 of temperature stations at the five-cluster level. retained and are presented here (Figs. 5-7). The main body stations in Cluster 1 spread from the southwestern Yukon along $60^{\circ} \mathrm{N}$ to Hudson Bay, including its southern shores. The cluster further includes all the stations in Iceland and Svalbard, and overlaps Cluster 5 in northern Norway. There are also two geographical outliers along the northern Canadian coast. In this cluster, there is moderate confidence in warming from early December to the end of January. Late February reveals a period of significant confidence in cooling taking place. In early May to early September there is primarily moderate confidence in warming having occurred, with the exception of two anomalous periods in the latter half of May and late June/early July. Confidence in a phase of cooling is moderate in October and lower in November, but high at the end of October and beginning of November.

The geographical coverage of member stations in Cluster 2 extends from Russia, east of approximately $135^{\circ} \mathrm{E}$, through Alaska, northern Canada, the Canadian Archipelago, northern Baffin Island, and northern Greenland. Significant confidence and strong agreement are shown for cooling in mid-January, with moderate confidence in cooling for the beginning and end of that month. There is moderate to strong confidence that warming has occurred from the beginning of April through mid-August, similarly followed by an abrupt change in pattern. Mid-November to early December and late December display moderate confidence that cooling has occurred.

Cluster 3 is the only cluster that displays complete spatial contiguity and has no overlap with other clusters. Its stations spread across Russia from approximately $135^{\circ} \mathrm{E}$ to the edge of Cluster 5, near the western Russian border, as well as across the most northern portion of Scandinavia. Characterizing Cluster 3 is significant confidence in the occurrence of warming in four out of six periods from late January until the end of March; moderate confidence is exhibited for mid-March, and anomalously low confidence is exhibited for late February. These four periods of significant confidence also display particularly high agreement between cluster members. Another period of probable warming is mid-May to early June. Another period with significant confidence in warming is observed in early October, flanked by two periods of moderate confidence. Early November is noteworthy as a period with very high agreement on a moderate level of confidence that cooling has occurred.

The distribution of Cluster 4 stations extends from southwestern Greenland and northeastern Canada, including southern Baffin Island, to the northwest of Hudson Bay. It also includes two geographical outliers, one on the northern Canadian coast and the other on the Aleutian Archipelago. Cluster 4 is most distinguished by significant confidence in cooling in late December and from midJanuary to mid-February. Late April to late June also appears to be a distinct period of cooling. Overall there exists little confidence in the occurrence of warming throughout the remainder of the year, with notable 
Cluster $1(\mathrm{~N}=1706)$

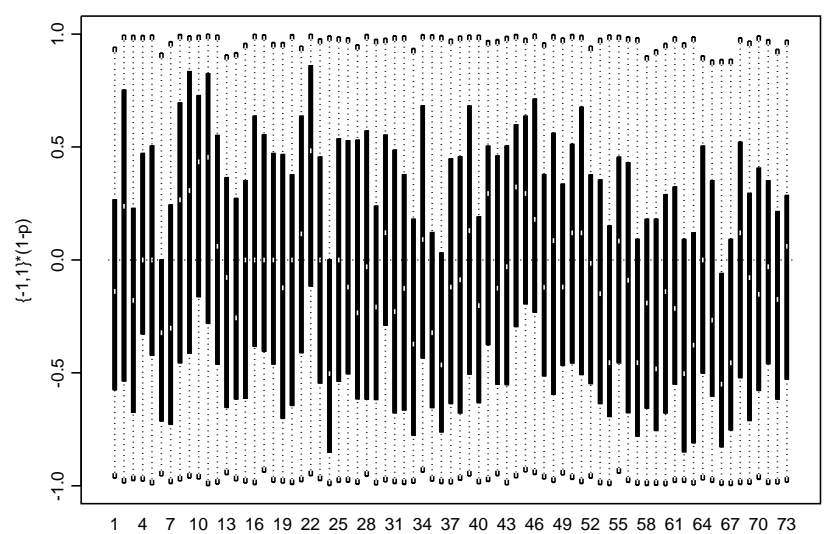

Period

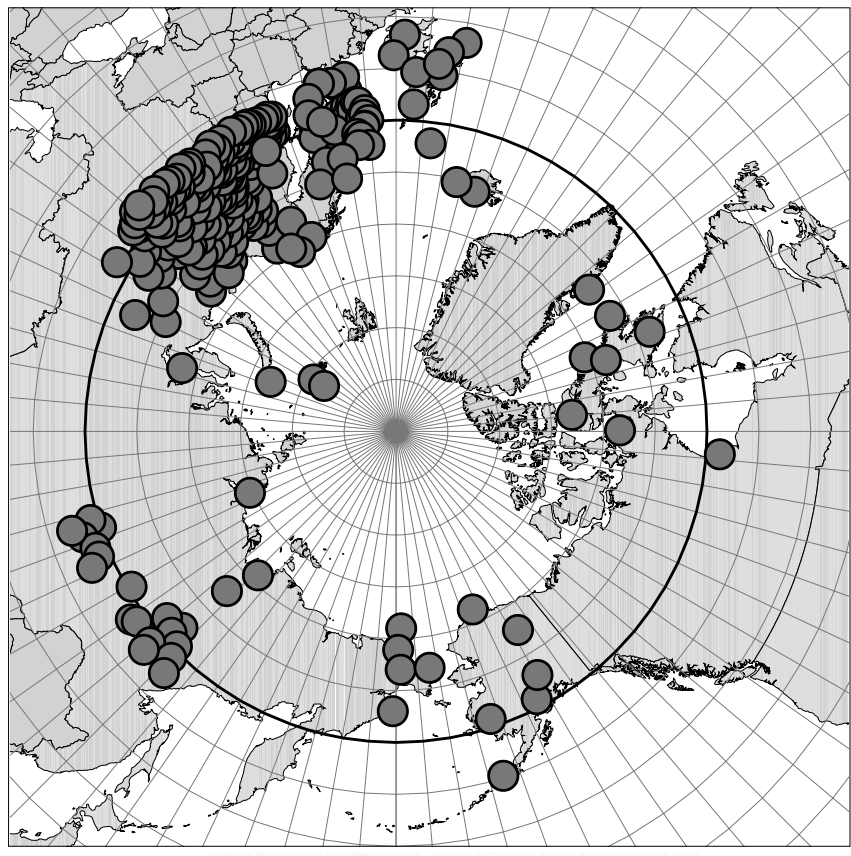

Decadal precipitation - daily data: 5 day averages 63800026069 BELOGORKA, RUSSIA

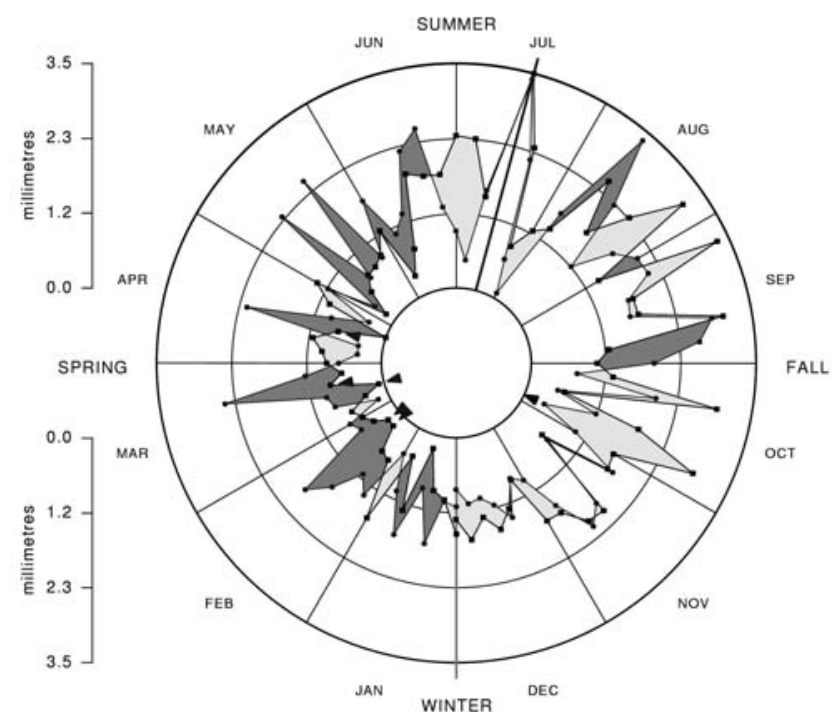

Cluster $2(\mathrm{~N}=1757)$

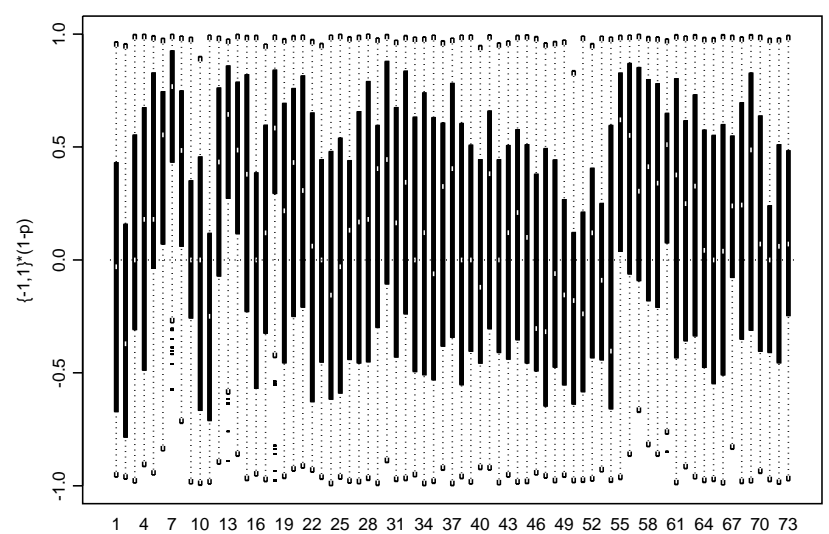

Period

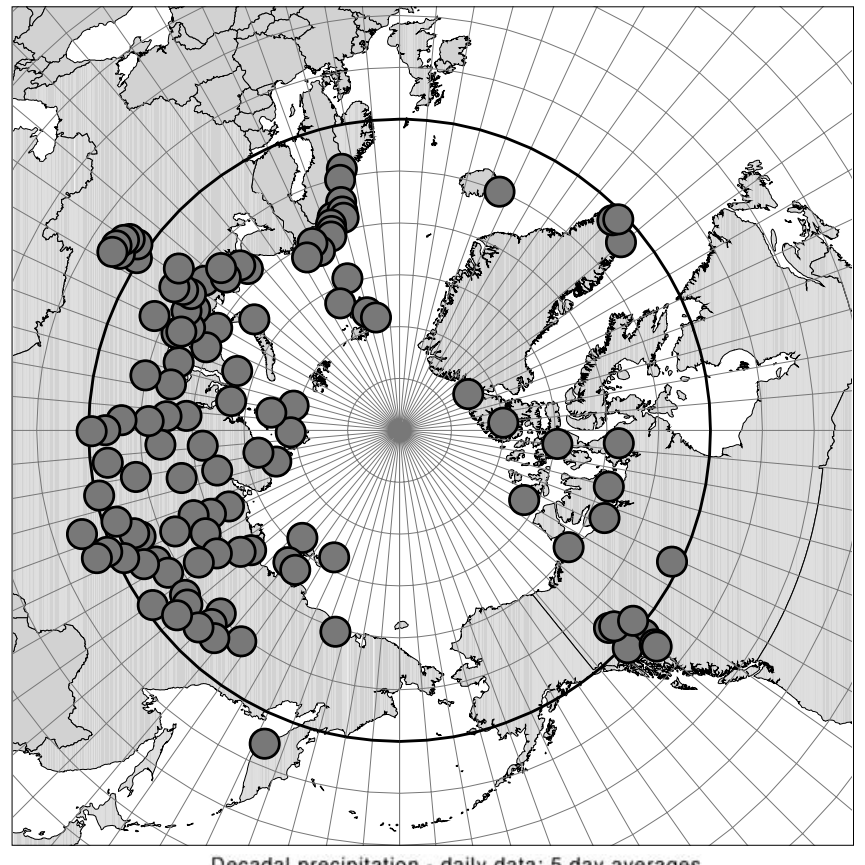

Decadal precipitation - daily data: 5 day averages 99710 BJOERNOEYA, NORWAY

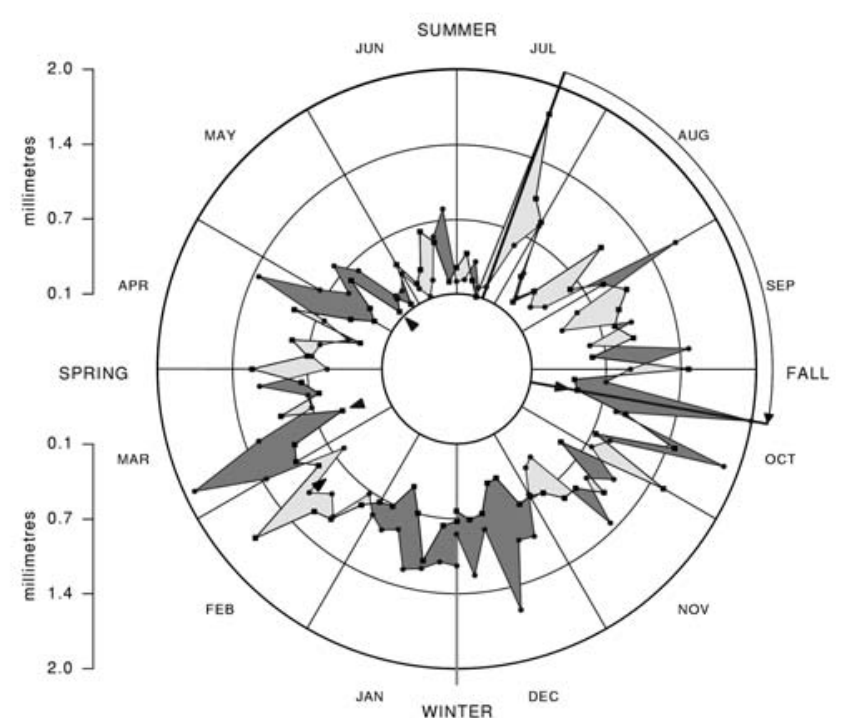

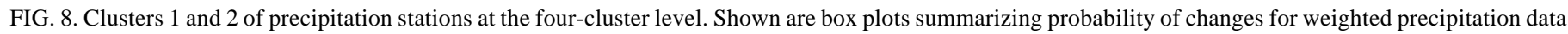

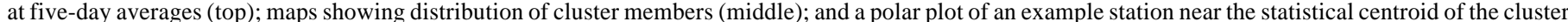

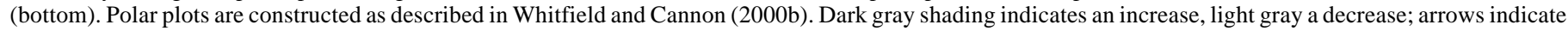
significant increases and decreases. 
exceptions only in early August and mid-December. Confidence that cooling has occurred is moderate during many periods, especially in the winter and spring.

The separation of Cluster 5 from Cluster 1 at the fivecluster level was a key factor in the decision to retain five clusters instead of four. The stations of Cluster 5 are spread from Estonia and the eastern Russian margin throughout Scandinavia and south to the United Kingdom and Ireland. There is significant confidence in episodes of warming from the beginning of January to mid-February, in the last three weeks of March, and from late April to mid-May, and many of these periods also exhibit especially strong agreement within the cluster. There is very strong agreement on moderate confidence in cooling in mid-April and moderate to strong confidence in cooling from mid-May to early June. Moderate confidence in warming is displayed from mid-June to early August, followed by lower confidence in a generally cooling phase until the end of September. Moderate confidence in warming is observed from early November until the end of December, except in late November.

\section{Precipitation Cluster Results}

The weighted results from 555 precipitation stations were included in the clustering process. Four clusters were retained and are presented here (Figs. 8-9). The increased number of stations, finer time-step, and greater variability inherent in precipitation generated results that are more difficult to interpret. During much of the year, in many of the clusters the high level of inter-periodic variation makes details less clear; hence, we limit ourselves to broad generalizations of patterns.

Stations from the Ural Mountains through to Ireland, with the exception of northern Norway, are predominantly members of Cluster 1. Cluster 1 members also constitute the majority of stations on Baffin Island, in the western Alaska/Bering Sea region, and in a band stretching across southeast Russia. The cluster also includes other stations interspersed throughout northern Russia, central Canada, Greenland, and Iceland. In this cluster, February displays moderate confidence that increases in precipitation have occurred. Generally, there is slight to moderate confidence that decreases have occurred from the end of April until mid-July. Late summer generally reveals only slight confidence in increased precipitation. Slight to moderate confidence in increases is shown from early October through November.

Cluster 2 consists of the majority of stations distributed throughout central Russia, the northern Russian islands, northern Norway, Svalbard, and the Canadian Archipelago. Significant station groups are also found in western Canada, at the intersection of Cluster 3 and Cluster 4, as well as at the southern tip of Greenland; notable outliers are located in Iceland and on the Kamchatka Peninsula. There is moderate to strong confidence that increases in precipitation have occurred in late January to early February and late February to mid-March. April to August generally displays slight to moderate confidence in increasing precipitation. Another episode with moderate confidence in increases occurs during October.

Cluster 3 stations spread from central Alaska through northern Canada and the Hudson Bay/southeastern Canadian Archipelago region to Greenland and Iceland. A separate band of member stations stretches across southcentral Russia. Cluster 3 is characterized by the predominant occurrence of periods with slight, and sometimes moderate, confidence in precipitation decreases from early February to mid-August. Generally, the periods during this time show little confidence that increases have occurred. There is moderate confidence in increases in precipitation in September and slight confidence in increases during December.

The stations of Cluster 4 are located primarily in Russia east of $140^{\circ} \mathrm{E}$, in northeastern Canada, and within a band along $60^{\circ} \mathrm{N}$ in western Canada. There are two distinct geographical outliers in northwestern Russia. There is moderate confidence that precipitation decreases have occurred from early December through early February. Moderate confidence exists in the occurrence of increases during November. The remainder of the year is extremely variable, much more so than in the other clusters, with periods of increases and decreases, of slight to moderate confidence, interspersed among each other. Overall, there is a slight tendency towards low confidence in decreases.

\section{DISCUSSION}

A major issue in any study is maintaining the distinction between statistical clusters and their geographical expression. The goal of the cluster analysis is to achieve a purely statistical, objective clustering of the input stations. This may not always lead to results easily interpreted from a geographical standpoint. Spatial cohesiveness of clusters facilitates discussions on regional trends but it is the statistical cohesiveness of clusters that represents groupings of stations that truly display a similar pattern of change. Since the processes controlling climate operate on broad spatial scales, it follows that climate stations in any given region will be subject to similar driving forces; therefore, it would be expected that climate stations found to have similar patterns of change would also be located in similar regions. In this study and previous work, it has been anticipated that the statistical cohesiveness of clusters will generally be reflected as spatial cohesiveness in the distribution of cluster members. This relationship is largely evident in the analysis of precipitation stations, but much more strongly illustrated in the analysis of temperature stations.

The temperature and precipitation clusters defined in this study provide a useful baseline for future examination of climate change in the circumpolar Arctic. These clusters provide a definition of regions displaying similar patterns 
Cluster $3(\mathrm{~N}=1356)$

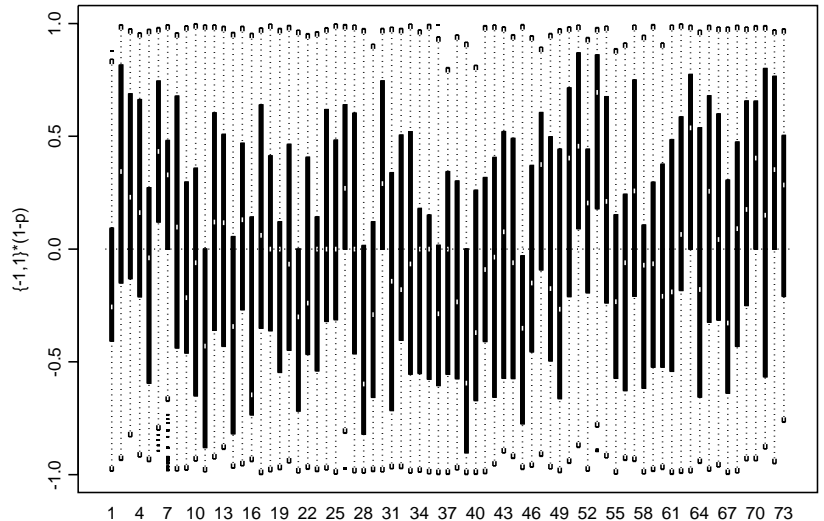

Period
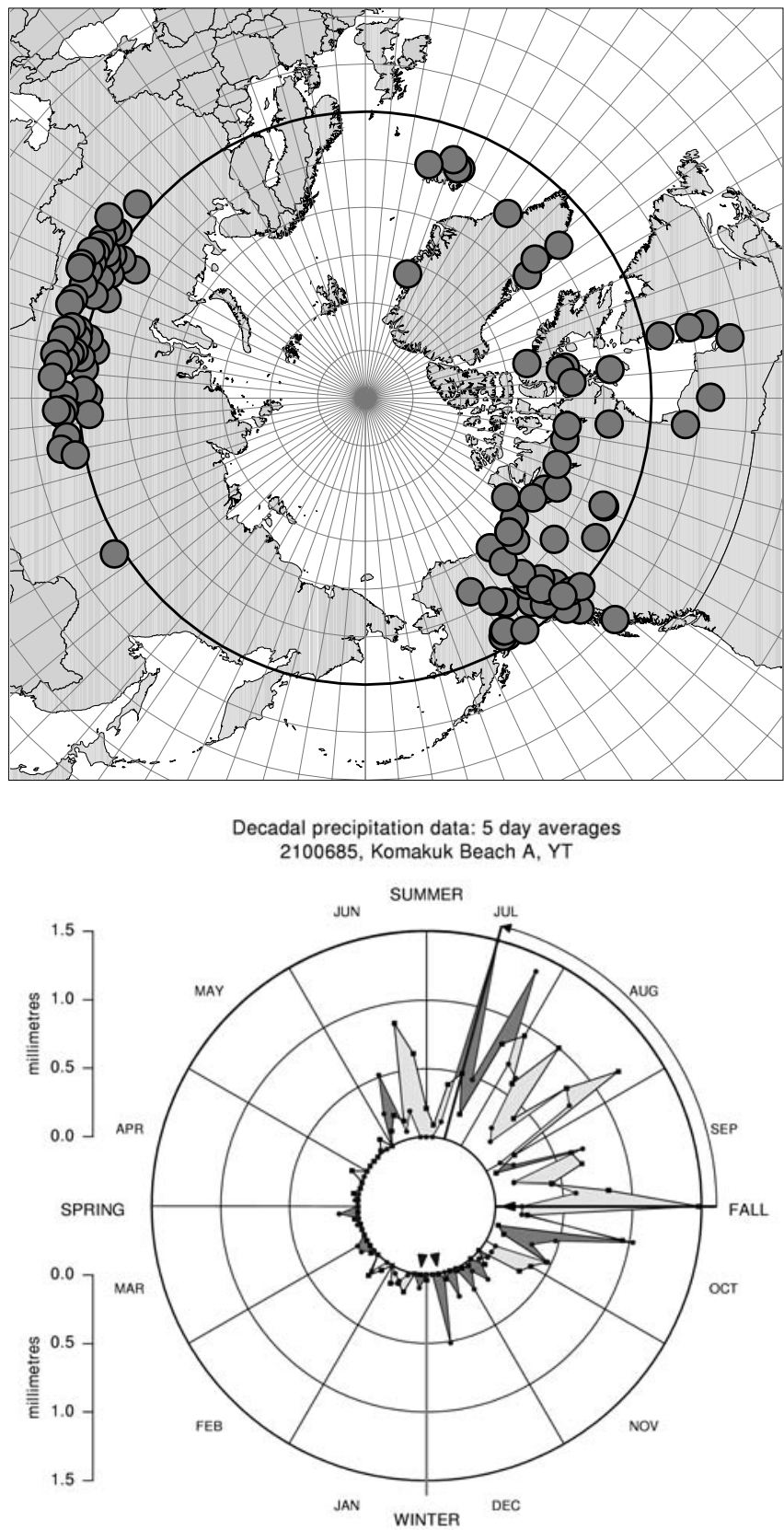

Cluster $4(\mathrm{~N}=866)$

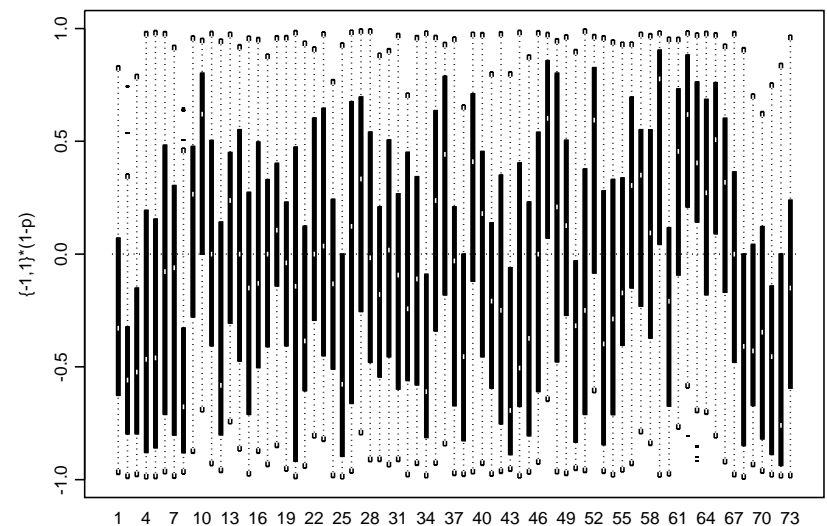

Period

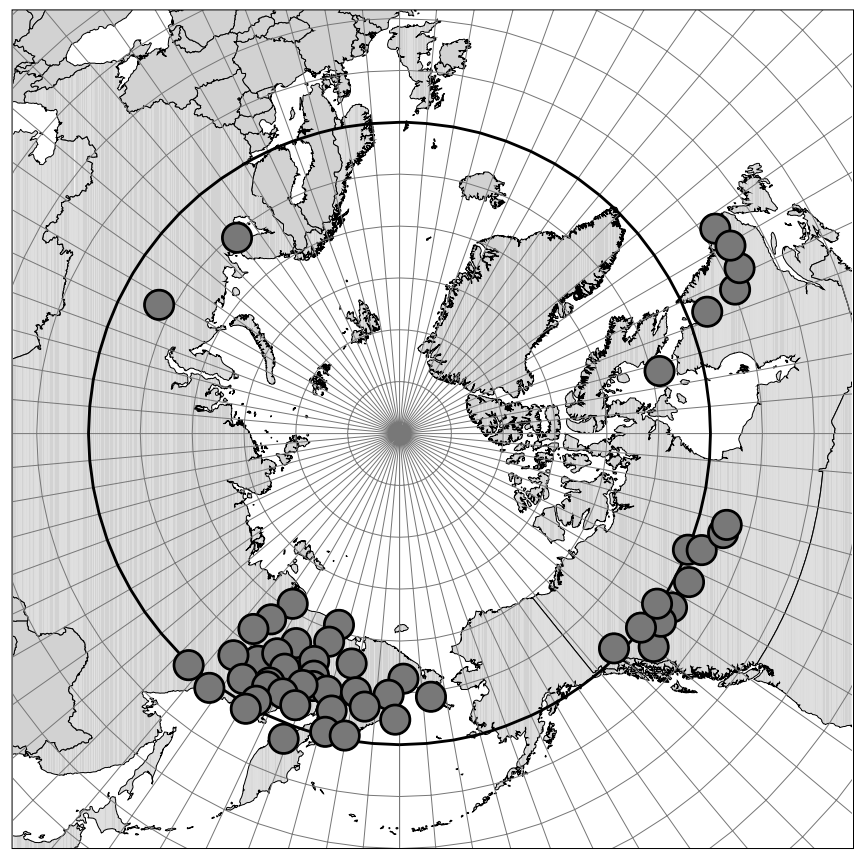

Decadal precipitation - daily data: 5 day averages 22200025744 KAMENSKOE, RUSSIA

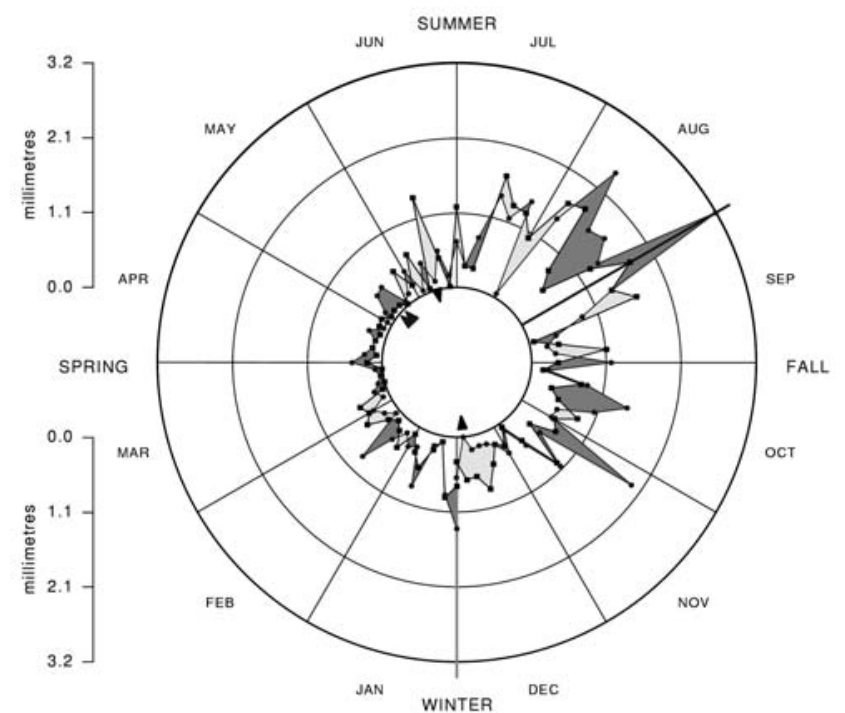

FIG. 9. As in Fig. 8, but for clusters 3 and 4 of precipitation stations at the four-cluster level. 
of inter-decadal change. Those regions could be the basis for examinations of additional Arctic climate properties, such as the spatial distribution of longer-term trends.

Many authors have examined trends in time series, whereas we are alternatively examining the spatial distribution of more recent fine time-scale variations in the seasonal pattern. Yet, the results for clusters identified in this study share similarities with the results of studies presented by other authors in studies of longer-term trends. Bonsal et al. (2001) found that from 1950 to 1998, northeastern Canada had experienced substantial cooling during the winter and moderate cooling in the spring, but displayed no significant trend in the summer and autumn. These patterns are apparent in Cluster 4, which corresponds to a similar region; however, by examining a finer timescale, we are able to provide a much more detailed analysis than seasonal generalizations. For example, we can show that the winter cooling phase begins in late December, is strongest across the region in the last three weeks of January, and tapers off during February. Our observations of winter cooling through eastern Siberia, Alaska, and the Beaufort Sea region agree with those of Rigor et al. (2000), as do our observations of winter warming in eastern Greenland, Iceland, and Scandinavia to central Russia. Once again our analyses render a more precisely defined time signal for such shifts.

For 20th century precipitation, New et al. (2001) show that there is a relatively large positive trend for the zone from $60^{\circ}$ to $80^{\circ} \mathrm{N}$. Our results reveal more detailed patterns within the year. Hurrell (1995) observed that in response to the North Atlantic Oscillation's remaining in a positive mode since the early 1980 s, winter precipitation has increased over Scandinavia, and precipitation has generally increased over northern Europe. By examining Cluster 2, to which northern Scandinavia belongs, we can show that winter increases in precipitation have been most evident in late January to early February and again from late February to mid-March. The increases in northern Europe (Cluster 1) appear to have occurred mostly in mid-winter, late summer, and the latter half of autumn. Hurrell (1995) also observed generally declining rates of precipitation over Greenland and increases over northeastern Quebec. The results of Clusters 3 and 4, respectively, are in agreement with these observations, but are able to provide greater information on the seasonal timing of these changes.

\section{CONCLUSION}

In the present study, we started with records of approximately 1200 Arctic climate stations for the period 197695. Temperature and precipitation records were analyzed using 11-day and 5-day averages, respectively. For the 802 stations that met our completeness criteria, we employed previously reported methodology to determine the significance of differences between the two decades that occurred within each period. These results were then clustered in order to identify subsets of stations for which the patterns of change are similar. The clustering of the stations was based solely on their patterns of change, but when mapped, the clusters also exhibited a high level of spatial contiguity. The result was the identification of regions where sites had similar patterns of change from the first decade (1976-85) to the second (1986-95).

In this study, our purpose was to identify regions displaying similar patterns of change from the first to the second decade, but not to associate causation factors with the observed shifts. We identified periods and directions of inter-decadal change that were significant with respect to the intra-decadal variation of the first decade, but the period of record examined is not extensive enough to determine whether or not these shifts are truly significant with respect to long-term natural fluctuations. However, these two decades are pertinent for linking to studies of recent ecological changes in the North. The clusters established in this study define regions that have been responding in a similar fashion recently, but there is a need for an examination of the long-term changes within these clusters to determine whether such similarities have persisted through a longer period of time or are a more recent development. Temperature and precipitation clusters defined in this work provide a useful framework for such analyses of long-term trends.

\section{ACKNOWLEDGEMENTS}

The authors would like to thank Eirik Førland of the Norwegian Meteorological Institute for providing a supplementary data set of stations in Norway and Svalbard; John Cappelen of the Danish Meteorological Institute for providing data for stations in Greenland and the Faroe Islands; and Pasha Groisman of the U.S. National Climate Data Center for providing data for Alaskan and Russian stations, as well as for additional stations in Greenland and Iceland. We appreciate the suggestions and comments made by the reviewers of our manuscript.

\section{REFERENCES}

AHAS, R., AASA, A., MENZEL, A., FEDOTOVA, V.G., and SCHEIFINGER, H. 2002. Changes in European spring phenology. International Journal of Climatology. 22:1727-1738.

AMAP (ARCTIC MONITORING AND ASSESSMENT PROGRAMME). 1998. Physical/geographical characteristics of the Arctic. In: Arctic Pollution Issues: A State of the Arctic Environment Report. Chapter 2. Oslo: AMAP. 9-24.

BONSAL, B.R, ZHANG, X., VINCENT, L.A., and HOGG, W.D. 2001. Characteristics of daily and extreme temperatures over Canada. Journal of Climate 14:1959-1976.

BRADLEY, R.S., DIAZ, H.F., EISCHEID, J.K., JONES, P.D., KELLY, P.M., and GOODESS, C.M. 1987. Precipitation fluctuations over Northern Hemisphere land areas since the mid19th century. Science 237:171-175. 
CALINSKI, R.B., and HARABASZ, J. 1974. A dendrite method for cluster analysis. Communications in Statistics 3:1-27.

CAYAN, D.R., KAMMERDIENER, S.A., DETTINGER, M.D., CAPRIO, J.M., and PETERSON, D.H. 2002. Changes in the onset of spring in the western United States. Bulletin of the American Meteorological Society 82:399-415.

FLEMING, S.W., and CLARKE, G.K.C. 2002. Autoregressive noise, deserialization, and trend detection and quantification in annual river discharge time series. Canadian Water Resources Journal 27:335-354.

GRENFELL, B.T., WILSON, K., FINKSTADT, B.F., COULSON, T.N., MURRAY, S., ALBONI, S.D., PEMBERTON, J.M., CLUTTON-BROCK, T.H., and CRAWLEY, M.J. 1998. Noise and determinism in synchronized sheep dynamics. Nature 394:674-677.

HUBERT, J.L., and LEVIN, J.R. 1976. A general statistical framework for assessing categorical clustering in free recall. Phycological Bulletin 83:1072-1080.

HURRELL, J.W. 1995. Decadal trends in the North Atlantic Oscillation: Regional temperature and precipitation. Science 269:676-679.

IPCC (INTERGOVERNMENTAL PANEL ON CLIMATE CHANGE). 2001. Polar regions (Arctic and Antarctic). In: McCarthy, J.J., Canziani, O.F., Leary, N.A., Dokken, D.J., and White, K.S., eds. Climate change 2001: Impacts, adaptation and vulnerability. Contribution of Working Group II to the Third Assessment Report of the Intergovernmental Panel on Climate Change. Chapter 16. New York: Cambridge University Press. 803-841.

JAGER, J., and KELLOG, W.W. 1983. Anomalies in temperature and rainfall during warm Arctic seasons. Climatic Change 5:3960.

KARL, T.R., and RIEBSAME, W.E. 1984. The identification of 10- to 20-year temperature and precipitation fluctuations in the contiguous United States. Journal of Climate and Applied Meteorology 23:950-966.

KATTSOV, V.M., and WALSH, J.E. 2000. Twentieth-century trends of Arctic precipitation from observational data and a climate mode simulation. Journal of Climate 13:1362-1370.

LEITH, R.M.M., and WHITFIELD, P.H. 1998. Evidence of climate change effects on the hydrology of streams in south-central B.C. Canadian Water Resources Journal 23:219-230.

LIKAS, A., VLASSIS, N., and VERBEEK, J.J. 2003. The global kmeans clustering algorithm. Pattern Recognition 36:451-461.

MILLIGAN, G.W., and COOPER, M.C. 1985. An examination of procedures for determining the number of clusters in a data set. Psychometrika 50:159-179.

MILNER, J.M., ELSTON, D.A., and ALBON, S.D. 1999. Estimating the contributions of population density and climatic fluctuations to interannual variation in survival of Soay sheep. Journal of Animal Ecology 68:1235-1247.

MOLNÁR, P., and RAMÍREZ, J.A. 2001. Recent trends in precipitation and streamflow in the Rio Puerco Basin. Journal of Climate 14:2317-2328.

NEW, M., TODD, M., HULME, M., and JONES, P. 2001. Review: Precipitation measurements and trends in the twentieth century. International Journal of Climatology 21:1899-1922.
PAETH, H., HENSE, A., and HAGENBROCK, R. 2002. Comments on 'Twentieth-century trends of Arctic precipitation from observational data and a climate mode simulation.' Journal of Climate 15:800-803.

POLAR GROUP. 1980. Polar atmosphere-ice-ocean processes: A review of polar problems in climate research. Reviews of Geophysics and Space Physics 18:525-543.

POST, E., and FORCHHAMMER, M.C. 2002. Synchronization of animal population dynamics by large-scale climate. Nature 420:168-171.

RIGOR, I.G., COLONY, R.L., and MARTIN, S. 2000. Variations in surface air temperature observations in the Arctic, 1979-97. Journal of Climate 13:896-914.

ROUSE, W.R., DOUGLAS, M.S.V., HECKY, R.E., HERSHEY, A.E., KLING, G.W., LESACK, L., MARSH, P., McDONALD, M., NICHOLSON, B.J., ROULET, N.T., and SMOL, J.P. 1997. Effects of climate change on the freshwaters of Arctic and Subarctic North America. Hydrological Processes 11:873-902.

SCHWARTZ, M.D., REED, B.C., and WHITE, M.A. 2002. Assessing satellite-derived start-of-season measures in the conterminous USA. International Journal of Climatology 22:1793-1805.

WAlTHER, G.-R., POST, E., CONVEY, P., MENZEL, A., PARMESAN, C., BEEBEE, T.J.C., FROMENTIN, J.-M., HOEGH-GULDBERG, O., and BAIRLEIN, F. 2002. Ecological responses to recent climate change. Nature 416:389-395.

WEINGESSEL, A., DIMITRIADOU, E., and DOLNICAR, S. 2002. An examination of indexes for determining the number of clusters in binary data sets. Psychometrika 67:137-160.

WHITFIELD, P.H. 2001. Linked hydrologic and climate variations in British Columbia and Yukon. Environmental Monitoring and Assessment 67:217-238.

WHITFIELD, P.H., and CANNON, A.J. 2000a. Recent variations in climate and hydrology in Canada. Canadian Water Resources Journal 25:19-65.

. 2000b. Polar plotting of seasonal hydrologic and climatic data. Northwest Science 74:76-80.

WHITFIELD, P.H., and TAYLOR, E. 1998. Apparent recent changes in hydrology and climate of coastal British Columbia. In: Alila, Y., ed. Mountains to sea: Human interaction with the hydrologic cycle. Proceedings of the 51st Canadian Water Resources Association Conference. 22-29.

WHITFIELD, P.H., BODTKER, K., and CANNON, A.J. 2002. Recent variations in seasonality of temperature and precipitation in Canada-1976-1995. International Journal of Climatology 22:1617-1644. 